\title{
Big data assists the government's Public Governance Innovation
}

\author{
Guo Xinyu \\ School of Finance and Public Management, \\ Yunnan University of Finance and Economics \\ Kunming, P.R. China \\ gxy0871@163.com
}

\begin{abstract}
The introduction to information technology will surely promote the innovation and transformation of government public governance. Based on the background of big data era, this article studies the government governance mode, analyzes the dilemma faced by the government governance innovation, and puts forward the relevant countermeasures and suggestions to promote the innovation of government governance, and finally realizes the goal of creating the wisdom government.
\end{abstract}

Keywords-big data; government governance; innovation

\section{INTRODUCTION}

The basis of science is data. Now a profound data revolution is changing the government's management model. Getting the data means getting the world. The Platform for Action on promoting big data's Development, issued on August 19, 2015, which gives a development direction to big data from the perspective of national strategy and has made a top level plan for it. In 2018, China's government work report clearly proposed the development of China's development of big data development action, and big data will become an important part of the government's governance innovation driven development.

\section{THE MEANING OF THE BIG DATA ERA}

The earliest formulation of the term Big Data came from the IT industry and was later applied to the business field. The characteristics of big data can be basically expressed in four $\mathrm{V}$, that is, Volume, Variety, Value, Velocity, which means mass, diversity, low value density,and speedability. From a narrow point of view, big data is the data owned and managed by the government,such as transportation, medical treatment, employment, health, public security culture, education, finance, statistics, meteorology, geography, environment and so on.

\section{BIG DATA PROMOTES GOVERNMENT INNOVATION}

Big data is the source of breaking new ideas and producing new creativity. Today, the use of information technology to achieve "data governance" has become a new tool for the developed countries like U.S.A. to change government decision-making procedures and ways of governance. It is an important tool for building a data platform based government, a service-oriented government, an open government, and an intelligent government.

As a decision-maker and manager of social affairs, the government should firstly be the recorder and owner of the mass data of the whole society. The more the data is mastered, the more it is beneficial to the government's decision. Secondly, the government should be the sorter and deep analyst of the data, disordered data need to be classified according to the needs of the decision. Finally, the government should use the data to make benchmarking and priority service providers, make the big data a public resource shared by the people, not only the government patent. In this transformation, the management mode of government personnel will be changed from experience management, document management and approval management into data management, data analysis, and data service. The big data is not only a technological change, but also a social change, which is accompanied by and calls for the reform of public administration and public service.

The big data will make the society more open, and make social rights more like a network, and the open society will make the government governance more open and transparent, from the administrative dominant to the people-oriented service government. In the future, government governance will pay more attention to individualized every citizens, not the general public, pay attention to the interaction of people, information and space rather than simple management, control or educate. To use objective data to make decisions will change the pattern of making head decisions in the past. management based on personal experience in the past, from mind to the data decision. First of all, using the new analysis ideas and analytical tools in the era of big data, the government can broaden the government's governance thinking and make more effective and accurate prediction. Secondly, the government governance structure is converted to the open and cooperative style, and the methods of governance are richer. Thirdly, through the Internet, the communication between the government and the society is more smooth, and everyone who is a source of data can communicate with the government to achieve consultation and the cooperation between government and citizens will come true. In short, big data makes government governance more refined, intelligent and standardized.

\section{BIG DATA'S GOVERNMENT APPLICATION}

Big data is a new motivation to change the government's approach to social governance. With the advancement of big data application technology, the value of big data becomes more obvious. The government has massive resources of big data,If it is used properly, it will greatly promote economic development, improve government service and supervision capabilities, and improve social governance.

Big data's typical application in the Smart City Service platform can include the following: 


\section{A. Urban Construction Planning}

Through the analysis and application of big data, it provides strong decision-making support for the government to delimit the locations of various supporting facilities such as the construction of CBD, industrial parks, hospitals, subways, schools, entertainment venues, libraries, and sports fields.

\section{B. Public safety}

In the field of public security,monitoring and early warning, analysis and prediction, and command and dispatch integration are realized through big data platforms. To assist the public security departments to grasp Urban Public security situation in all directions in real time, to realize the visualization of service management.Quickly check the deployment and dispatch of police force to provide data assistance for prejudging the police situation.

\section{Medical Treatment and Public Health}

Big data search can help the country to find outbreaks and multiple diseases as early as possible, and help hospitals and medical research institutes to better track and analyze medical effects and improve drug research and development capabilities.It can help people to choose big data of hospital doctors, and carry out long-term health analysis of big data according to individual medical records.

\section{D. educational resources}

The government can use big data to integrate all kinds of resources, promote education

informatization, achieve the circulation of high-quality educational resources on and off line, and distribute high-quality education resources more rationally.To change the existing knowledge transfer method which can not meet the actual needs. The coverage of quality education resources will be enlarged to reduce the gap between urban and rural areas and regions, to promote educational equity, improve teaching quality and provide personalized lifelong online learning services for all learners.

\section{E, Public transit}

The government builds a traffic operation detection and command system, uses integrated video monitoring system, through cloud computing cloud storage integrated data to draw complete traffic real-time images, realizes overall control of traffic conditions, and fundamentally realizes intelligent management of urban traffic.

\section{THE PROBLEM OF GOVERNMENT GOVERNANCE}

\section{INNOVATION IN THE BIG DATA ERA}

At the national level, the planning and design of big data projects is complete and rigorous, but the implementation of big data planning is faced with practical difficulties, and it is difficult to achieve the desired results.

\section{A. The government lacks the awareness of big data}

\section{governance}

Chinese culture does not admire fine and meticulous accounting management. Leaders are not used to using logic thinking of statistics, linear, and advanced mathematics in management. They believe in intuition and visualization. The feudal ideology of "official standard" of vertical leadership of one-way communication is inconsistent with the idea of implementing public governance by data at present. It is a cultural conflict. After "pilot", the governance of policy based on experience is tired and runs counter to the idea of digital public governance. The government also lacks the awareness of data mining, collection and analysis. The actual operation of big data governance, and the traditional governance methods are totally different. Leaders at all levels are lack of relevant knowledge reserves and difficult to use. Therefore, even though the advanced nature of big data has been realized, the traditional governance is still used.

\section{B. Lacking of big data's technical talents, the overall \\ management mechanism of big data is not perfect}

The Chinese government has mastered about $80 \%$ of the social information data, but on the one hand, the social value behind the data cannot be scientifically and effectively analyzed for the data processing clerks are government managers instead of professional big data specialists. On the other hand, because the platforms of various government departments are not connected, these data cannot be shared. Although the government and various departments at all levels have built the e-government platform, but because there is no unified government big data platform management institutions, most of the business systems are maintained and developed by different third-party IT companies. Because of the disunity of the data resources in various departments, it is easy to create the dilemma of "Nine Dragon water-control". In addition, the service cannot keep up, the system maintenance is broken, resulting in incomplete information in the business system. At last, the effective data information is very limited, and big data become an empty talk.

\section{Separation of interests is difficult to resolve}

For a long time, our country has pursued the organizational governance structure of the bureaucracy system, and communication among various levels in a department far exceeds the communication among departments, and the information sharing among the departments is particularly lacking. Therefore, some departments do not have the awareness of data opening, and our country does not impose restrictions on the laws and regulations on sharing and opening the data.As a result, some departments regard the data they hold as a tool to preserve their power and interest. They are not willing to share because they are afraid that once data is not monopolized by them, they will lose the power to obtain benefits from it.

\section{Personal privacy is threatened}

The data space constructed by big data is a combination of data mining from the sample to the whole, from the approximate to the precision, from the causal to the correlation degree, and the multi-source cross boundary data, which requires the interconnection and intercommunication between the depth and the breadth of the information. Only in this way can we analyze the valuable information from the mass information. In the process of emphasizing information disclosure and interconnection, it also brings challenges to some covert information protection. How to find a balance between information disclosure and covert protection is a realistic problem that the government needs to solve. 


\section{APPLICATION OF BIG DATA TO THE INNOVATION OF}

\section{GOVERnMENT Public Governance}

The way to solve the predicament mentioned above can be adopted in the following ways:

\section{A. Strengthening the concept of data governing}

Make big data the technical path and technical support of government governance, and form the thinking of openness, integration and sharing of big data information. China is the biggest country in the world of Internet use. China's information utilization rate is less than $1 / 10$ of the United States. Because of lack of "big data" consciousness, many data can not be collected and stored and can not be used effectively. Big data awareness is the basis of developing big data strategy. We should make long-term plans, enhance the concept of big data, optimize service consciousness, eliminate official standard thought, use data to speak, and do data analysis. The governance based on experience and lack of data will be changed to the more extensive analysis of the governance model of big data to make government work more efficient and scientific.

\section{B. Training big data talents and renewing working methods}

Train data managers to adapt to big data environment, strengthen the transformation of knowledge structure of managers, strengthen the training of existing managers and improve the structure of training courses to meet the requirements of big data management. Cultivate data management talents equipped with multi-directional knowledge structure with the help of universities, bring in excellent data management talents from other places and form a human resource structure which can satisfy new situations to adapt to the implementation of big data. At the same time, a simple and easy to operate big data analysis tool is introduced to enable the operation of big data analysis platform to be popularized.

\section{Establishing a unified decision-making platform}

We should improve the original decentralized management mode of various departments and establish a new connected management structure. The Central authorities actively advocates and promotes unified standardization, eliminates the data difference among various departments, and integrates the industry data, the accumulated historical data and the new social data, and establishes a unified big database to make the government in data acquisition advantages can be realized. Breaking the hierarchy structure, breaking the data sharing barrier, allowing the relevant departments to query the data from the platform, and introducing the business partners, using the data management technology of the enterprise, to overcome the application obstacles, and achieve multi win.

\section{To protect privacy in many ways}

Facing the big data age characterized by complexity, diversification and fragmentation, the existing legal framework is not good enough to protect citizens' right to privacy. In particular, after the government's gradual public data, everyone may become a "transparent person". Therefore, it is necessary to establish a kind of privacy protection mechanism that can balance the public and personal interests; On the one hand, data users must bear the legal responsibility to use the data, on the other hand, by blurring the data parts, it is not easy to excavate the individual specific data, thus the privacy of citizens is protected.After the specific rules are fully investigated, the administrative organs or industry associations shall draft the protection rules, and when the practice is mature, the appropriate time will be chosen to become the law. In addition, legislation is also needed to avoid national security and public safety problems caused by data opening.

\section{CONCLUSION}

One of the criteria for judging the degree of development in modern society is the ability to control the numbers. When the government uses the tool of good data, it can provide better service to the public. However, if the actual operation process become a mere formality, each department's data is in its own rights, the cooperation efficiency is low. It is excessively pursuing the interest of the department and personal interests, while ignoring the public interest, the government big data project will take more detours. Big data governance can not be achieved overnight. After a lot of experience and lessons, big data technology will promote the transformation of government governance from authority governance to scientific governance. We expect the government to implement such a big data strategy to improve the quality of life of the people and look forward to the arrival of the era of wisdom government.

\section{ACKNOWLEDGMENT}

I'd like to show my gratitude to my family and friends who have always given me a lot help and support.

\section{REFERENCES}

[1 ] Cao Qingmei, government statistics services research on public issues [J] research world, 2014[1]:43-46(In Chinese)

[2] Jin Jiang army, Xu Jing, Wang Weiling. Research on development strategy of government big data [J], China information circles, 2013 (9):62-64(In Chinese)

[3] Viktor M S, Kenneth C. Big data: a revolution that will transform how we live, work and think[M]. Hangzhou: Zhejiang People's Publishing House, 2012(In Chinese)

[4] Xu Jihua, Feng Qina, Chen Zhen Lu. Wisdom Government: the advent of the era of big data governance [M]. Beijing: CITIC press, 2014(In Chinese) 